\title{
Sequencing and phylogenetic analysis of infectious bronchitis virus variant strain from an outbreak in egg-layer flocks in Baghdad, Iraq
}

\author{
Abdullah O. Alhatami ${ }^{(\mathbb{D}}$, Furkan Alaraji2 ${ }^{\mathbb{D}}$, Husam Muhsen Abdulwahab ${ }^{(\mathbb{D})}$ and Yahia Ismail Khudhair ${ }^{3}$ (D) \\ 1. Department of Microbiology, Faculty of Veterinary Medicine, University of Kufa, Iraq; 2. Department of Pathology and \\ Poultry Diseases, Faculty of Veterinary Medicine, University of Kufa, Iraq; 3. Department of Internal and Preventive \\ Medicine, College of Veterinary Medicine, University of Al-Qadisiyah, Iraq. \\ Corresponding author: Furkan Alaraji, e-mail: furkans.alaraji@uokufa.edu.iq \\ Co-authors: AOA: abdullaho.mansour@uokufa.edu.iq, HMA: husamm.abdulwahab@uokufa.edu.iq, \\ YIK: yahia.khudiar@qu.edu.iq \\ Received: 05-02-2020, Accepted: 21-05-2020, Published online: 16-07-2020
}

doi: www.doi.org/10.14202/vetworld.2020.1358-1362 How to cite this article: Alhatami AO, Alaraji F, Abdulwahab HM, Khudhair YI (2020) Sequencing and phylogenetic analysis of infectious bronchitis virus variant strain from an outbreak in egg-layer flocks in Baghdad, Iraq, Veterinary World, 13(7): 1358-1362.

\begin{abstract}
Background and Aim: Infectious bronchitis (IB) has an influential economic impact on the poultry industry, causing huge losses each year due to the condemnation of infected chickens. Despite the use of many kinds of vaccines in Iraq, it is common to find IB problems in vaccinated chickens. Information about the strains that affect Iraqi chickens is very limited. Therefore, we aimed to detect the currently circulating strains of IB virus that cause frequent outbreaks in egg layers despite the use of vaccination against the virus.
\end{abstract}

Materials and Methods: Isolate detection, sequencing, and phylogenetic analysis were performed using a rapid IB virus antigen kit (32 tracheal swabs), flinders technology associates (FTA) card (32 tracheal swabs), and partial gene sequencing (16 positive FTA samples).

Results: The isolated strain was different from other strains, especially the strain isolated in the North of Iraq (Sulemania Strain) and shares 98\% homology with an Israeli strain (Israel variant 2, IS 1494).

Conclusion: Although more studies are needed to detect IB virus strains circulating in Iraq, this work lays the foundation for making a good strategy to control the disease and selecting vaccines that should be used in farms.

Keywords: infectious bronchitis, phylogenetic tree, poultry, real-time polymerase chain reaction, spike 1 gene.

\section{Introduction}

An important viral disease affecting the poultry industry globally and locally in Iraq is the infectious bronchitis virus (IBV), which causes an acute, highly contagious respiratory disease. The identification of endemic IBV strains promotes better control of the disease and prevents production losses [1]. IBV belongs to the family Coronaviridae and the genus Gamma-coronavirus. The single-stranded RNA (positive-sense, $\sim 30 \mathrm{~kb}$ ) of this enveloped virus has several open reading frames [2]. Although the nucleocapsid (N) gene is highly conserved among coronaviruses, the spike (S) glycoprotein (particularly S1) gene contains highly variable components in these viruses [3].

IBV usually is subjected to changes due to mutations and genetic recombination. Therefore, a mutation in the S1 gene may affect virus tissue tropism and virulence [4]. Consequently, IBV can spread widely to affect different regions of the world, creating huge difficulties in controlling the disease due to these newly

Copyright: Alhatami, et al. Open Access. This article is distributed under the terms of the Creative Commons Attribution 4.0 International License (http://creativecommons.org/licenses/ by/4.0/), which permits unrestricted use, distribution, and reproduction in any medium, provided you give appropriate credit to the original author(s) and the source, provide a link to the Creative Commons license, and indicate if changes were made. The Creative Commons Public Domain Dedication waiver (http:// creativecommons.org/publicdomain/zero/1.0/) applies to the data made available in this article, unless otherwise stated. modified strains $[3,4]$. Even with high numbers of the globally identified genotypes or serotypes of IBV, cross-protection generated by those strains is barely present [5]. The highly variable S1 gene represents the ideal genetic target for monitoring viral evolution occurring in IBV, especially in strains with high rates of serotype correlations [6]. Therefore, sequencing the $\mathrm{S} 1$ gene of IBV strains detected in the field is critical for control programs and epidemiological purposes. The spike protein is a major structural protein of 1162 amino acids that are cleaved into 535-AA-SP1 (S1, N-terminus) and 627-AA-SP2 (S2, C-terminus). The S1 gene induces serotype-specific based antibody neutralization through its two hypervariable regions [7]. Many polymerase chain reaction (PCR)based techniques have been developed to monitor the prevalence of IBV by targeting and analyzing the $\mathrm{S} 1$ gene. Reverse-transcriptase PCR (RT-PCR) and nucleotide sequencing of the $\mathrm{S} 1$ gene are routinely used to detect IBV genotype; in addition to real-time quantitative PCR (RT-qPCR), which also is used to identify IBV from field samples. These molecular methods are highly sensitive and specific compared with other diagnostic methods [8-10]. Since its discovery in 1931, and despite massive routine vaccination, IBV continues to be one of the major concerns in the poultry industry worldwide. This may be due to many reasons, one of which is the continuous emergence of 
new IBV strains [11] with unique genetic determinants identified in each geographical area.

To the best of our knowledge, only one study to date reports the molecular characterization of IBV that resulted in a broiler strain $(\mathrm{Sul} / 01 / 09)$, identified in the Kurdistan region of Iraq. Therefore, the current report describes the role of IBV during an outbreak of the respiratory disease in an egg-layer farm in the Baghdad region of Iraq, investigates the genetic characteristics of this field strain by analyzing the S1 gene and compares it with other isolates registered globally for developing significant vaccines to control this disease.

\section{Materials and Methods}

\section{Ethical approval}

This study does not require ethical approval. However, all birds in the current work were treated humanely following International and National criteria of animal care and use.

\section{Poultry farms}

An outbreak occurred during January 2018 in Al-Janoob Company, located in the Al-Wahda district of Baghdad, Iraq. This was composed of eight caged houses of egg layers with a total number of 640,000 hens and 170,000 rearing pullets. The outbreak was not reported to the national authority. All flocks were vaccinated with commercial live-attenuated NOBILIS IB 4-91. Respiratory symptoms began in 28-day-old birds of an ISA Brown flock composed of 88,000 birds per house. Clinically, the symptoms were suspected to be IBV infections. Necropsies were performed, and gross lesions were evaluated.

\section{Sample collection}

Sixty-four tracheal swabs (two swabs per bird) were collected during January 2018, from birds that showed such respiratory manifestations.

\section{Rapid IBV antigen detection}

Thirty-two tracheal swabs were used for serological diagnosis of IBV antigen using a Rapid IBV Ag Test Kit (RG1513DD, Bionote, Korea), which is a chromatographic immunoassay for qualitative IBV antigenic detection in avian swab samples. Tests were performed according to the manufacturer's instructions.

\section{RNA extraction}

Samples were pooled on flinders technology associates (FTA) cards (Whatman ${ }^{\circledR}$ FTA $^{\circledR}$ card technology) with four sample areas per card (total homogenate volume up to $100 \mu \mathrm{L}$ ) containing chemicals for lysing cells, denaturing proteins, and protecting nucleic acids against damage from nucleases, ultraviolet radiation, and oxidation [12,13].

FTA cards containing viral RNA were outsourced to AniCon Labor GmbH (Muehlenstraße 13a 49685 Hoeltinghausen, Germany), where the extraction of the IBV RNA was performed using $\mathrm{Kylt}^{\circledR}$ RNA/DNA Purification Kit through the manufacturer's protocol.

\section{Real-time RT-PCR}

RT-PCR runs were generated by AniCon Labor $\mathrm{GmbH}$. Briefly, species-specific and variant-specific RT-PCR methods were performed to detect avian coronavirus (aCoV, including IBV) and IBV variants. Hybridization probe-based chemistry was used with the following primers: Kylt ${ }^{\circledR}$ IB-aCoV, Kylt ${ }^{\circledR}$ IBV-Variant 02, Kylt ${ }^{\circledR}$ IBV-Variant 4/91 (793b), $\mathrm{Kylt}^{\circledR} \quad$ IBV-Variant Arkansas, Kylt ${ }^{\circledR}$ IBV-Variant D1466, Kylt ${ }^{\circledR}$ IBV-Variant D274, Kylt ${ }^{\circledR}$ IBV-Variant Italy02, Kylt ${ }^{\circledR}$ IBV-Variant Massachusetts, $\mathrm{Kylt}^{\circledR}$ IBV-Variant Q1, Kylt ${ }^{\circledR}$ IBV-Variant QX, and $\mathrm{Kylt}^{\circledR}$ IBV-IB80 (AniCon Labor GmbH). RT-PCR, CFX96, and CFX384 (Bio-Rad, Hercules, CA, USA) systems were used according to the following conditions: $50^{\circ} \mathrm{C}$ for $10 \mathrm{~min}$ and $95^{\circ} \mathrm{C}$ for $1 \mathrm{~min}$ (initial denaturation), then 42 cycles of $95^{\circ} \mathrm{C}$ for $10 \mathrm{~s}, 60^{\circ} \mathrm{C}$ for $1 \mathrm{~min}$, and read.

\section{Sequencing of S1 gene products and GenBank acces- sion number}

The amplified RT-PCR products were sequenced by AniCon Labor GmbH. Sequences of the IraqiIBV-strain S1 gene were deposited in the GenBank database available from the National Center for Biotechnology Information (NCBI) website to collect accession numbers.

\section{Sequences alignment and phylogenetic analysis}

IBV S1 gene sequences obtained herein were compared with sequences of IBV deposited globally in the GenBank database using the NCBI-based BLAST search. The identities of the sequences were analyzed by DNAstar software (DNASTAR, Madison, WI, USA; https://www.dnastar.com/), and Molecular Evolutionary Genetics Analysis (MEGA) X software (https://www.megasoftware.net/) were used to construct the phylogenetic tree.

\section{Results}

\section{Clinical signs and postmortem examinations}

The flock suffered from signs of infectious bronchitis (IB) disease, and the mortality rates reached $8 \%$ for approximately 10 days. Birds suffered the following symptoms: Coughing, sneezing, and rales with depression. Postmortem findings included tracheal congestion, and caseous materials that partially obstructed the trachea and the tracheal bifurcations, and pneumonia and fibrinous airsacculitis (Figure-1). Kidneys were enlarged and congested and contained an accumulation of urate in the nephrons and ureters.

\section{Rapid IBV antigen detection}

Thirty-two (100\%) of the examined samples were positive for the presence of the IBV antigen.

\section{Real-time RT-PCR}

Viral RNA from the FTA cards (four spots pooled) with the sample number (A1800428.001) showed positive results with species-specific and IBV-variant-specific RT-qPCR (Table-1). 


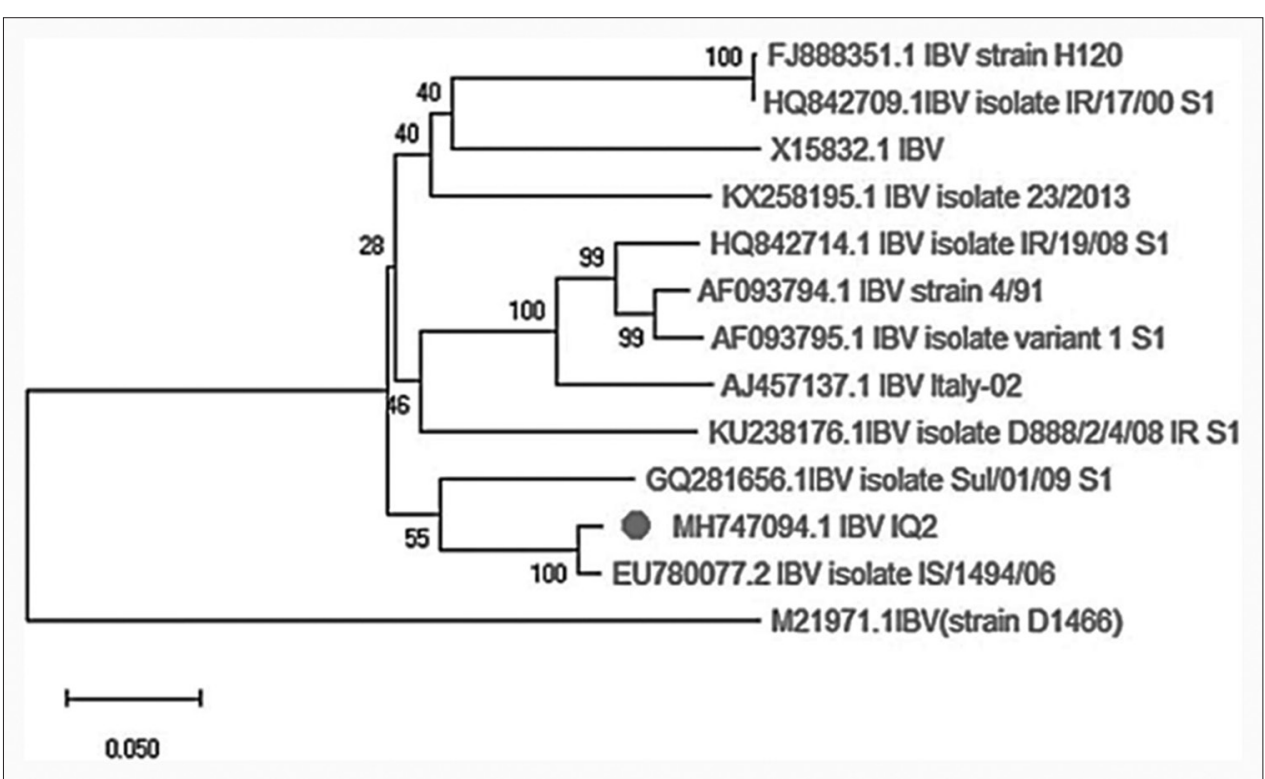

Figure-1: Phylogenetic tree of the infectious bronchitis virus based on the infectious bronchitis virus-IQ2 S1-spike gene partial sequencing with a comparison to world sequence databases.

Table-1: Avian coronavirus (aCoV incl IBV) and IB variant detection using species-specific and variant-specific RT-PCR.

\begin{tabular}{|c|c|}
\hline Sample no. & A1800428.001 \\
\hline \multicolumn{2}{|l|}{ aCoV inkl IBV ${ }^{1}$} \\
\hline Result & Positive \\
\hline $\mathrm{CT}$ & 17,1 \\
\hline \multicolumn{2}{|c|}{ 793b, 4/91, 1/96 and CR882 } \\
\hline Result & Not detected \\
\hline CT & - \\
\hline \multicolumn{2}{|l|}{ Massachusetts $^{2}$} \\
\hline Result & Positive \\
\hline $\mathrm{CT}$ & 29,9 \\
\hline \multicolumn{2}{|l|}{$\mathrm{D} 1466^{2}$} \\
\hline Result & Not detected \\
\hline $\mathrm{CT}$ & - \\
\hline \multicolumn{2}{|l|}{$\mathrm{D} 274^{2}$} \\
\hline Result & Not detected \\
\hline CT & - \\
\hline \multicolumn{2}{|l|}{ Italy $02^{2}$} \\
\hline Result & Not detected \\
\hline $\mathrm{CT}$ & - \\
\hline \multicolumn{2}{|l|}{ Arkansas ${ }^{2}$} \\
\hline Result & Not detected \\
\hline $\mathrm{CT}$ & - \\
\hline \multicolumn{2}{|c|}{ Variant2 $^{2}$ (Israel02, IS 1494) } \\
\hline Result & Positive \\
\hline $\mathrm{CT}$ & 15,7 \\
\hline \multicolumn{2}{|l|}{ IB $80^{2}$} \\
\hline Result & Not detected \\
\hline $\mathrm{CT}$ & - \\
\hline \multicolumn{2}{|l|}{ Q12 } \\
\hline Result & Not detected \\
\hline $\mathrm{CT}$ & - \\
\hline \multicolumn{2}{|l|}{$\mathrm{QX}^{2}$} \\
\hline Result & Not detected \\
\hline $\mathrm{CT}$ & - \\
\hline
\end{tabular}

(1) species-specific Real-Time RT-PCR: Detects Infectious Bronchitis Virus and Turkey Coronavirus, () IBV variant-specific RT-PCR. IBV=Infectious bronchitis virus, IB $=$ Infectious bronchitis, RT-PCR=Reverse transcriptasepolymerase chain reaction, FTA=Flinders technology associates, aCoV=Avian coronavirus
Sequencing of S1 gene products and GenBank accession number

A 630-bp and 730-bp fragments of the S1 protein-coding gene were sequenced by AniCon Labor $\mathrm{GmbH}$. The sequences were deposited in the NCBI GenBank under accession numbers MH747093 and MH747094 with the name aCoV strain IQ1 and IQ2 spike glycoprotein (S1) gene, respectively.

\section{Sequences alignment and phylogenetic tree}

The genetic relationship between the $\mathrm{S} 1$ gene sequence of the MH747094.1 IBV-IQ2 strain and sequences of vaccine and other virulent strains are presented in Figure-1 and Table-2. The MH747094.1 strain was closely related $(100 \%$ similarity $)$ to EU780077.2_IBV_isolate_IS/1494/06 (Israeli variant 2), whereas the percentage of sequence identity was 55\% compared with GQ281656.1IBV_isolate Sul/01/09_S1 (Sulaimania isolate). Moreover, the nucleotide similarity was $40 \%$ and $28 \%$ compared with FJ888351.1IBV strain H120 and AF 093794.1IBV strain 4/91, respectively.

\section{Discussion}

IB has an influential economic impact on the poultry industry, causing huge losses each year due to the condemnation of infected chickens [14]. Since IBV was identified during the early 1990s, IBV (4/91 type) has frequently been reported in Europe and many countries around the world [15]. IBV vaccine strains can perform recombination with field strains, reversing virulence [16]. Such characteristics have encouraged verification of the relationship between vaccine and field strains [17]. Although a 793/B-serotypebased attenuated vaccine is available, some 793/B-serotype viruses remain active in Europe and several countries [16], and the live-attenuated or killed Massachusetts (Mass) strain-dependent vaccines are 
Table-2: Percentage of nucleotide divergence of IBV-IQ2 strain in comparison to 12 IBV published isolates calculated by Mega X software.

FJ888351.1

IBV_strain_H120

KX258195.1

IBV_isolate_23/2013

HQ842714.1

IBV_isolate_IR/19/08_S1

HQ842709.1

IBV_isolate_IR/17/00_S1

GQ281656.1

IBV_isolate_Sul/01/09_S1

MH747094.1_

IBV_IQ2

EU780077.2

IBV_isolate_IS/1494/06

X15832.1_IBV

KU238176.1

IBV isolate

D888/2/4/08_IR_S1

AJ457137.1

IBV_Italy-02

M21971.1

IBV (strain_D1466)

AF093794.1 6

IBV_strain_4/91

AF093795.1.

IBV_isolate_variant_1_S1
0.21

\begin{tabular}{|c|c|c|c|c|c|c|c|c|c|}
\hline 0.25 & 0.23 & & & & & & & & \\
\hline 0.00 & 0.21 & 0.25 & & & & & & & \\
\hline 0.23 & 0.18 & 0.24 & 0.23 & & & & & & \\
\hline 0.19 & 0.21 & 0.21 & 0.19 & 0.13 & & & & & \\
\hline 0.21 & 0.22 & 0.20 & 0.21 & 0.13 & 0.02 & & & & \\
\hline 0.23 & 0.24 & 0.21 & 0.23 & 0.27 & 0.20 & 0.20 & & & \\
\hline 0.26 & 0.23 & 0.22 & 0.26 & 0.21 & 0.19 & 0.18 & 0.24 & & \\
\hline 0.27 & 0.25 & 0.11 & 0.26 & 0.20 & 0.22 & 0.22 & 0.24 & 0.21 & \\
\hline 0.54 & 0.53 & 0.51 & 0.54 & 0.48 & 0.51 & 0.50 & 0.56 & 0.53 & 0.52 \\
\hline 0.25 & 0.23 & 0.06 & 0.25 & 0.23 & 0.21 & 0.20 & 0.21 & 0.20 & 0.10 \\
\hline 0.26 & 0.24 & 0.07 & 0.26 & 0.23 & 0.21 & 0.21 & 0.22 & 0.20 & 0.12 \\
\hline
\end{tabular}

MEGA $X$ program software. in comparison to some selected strains. IBV=Infectious bronchitis virus

most widely used for vaccination programs throughout the world. Nevertheless, there is an increased failure of IBV vaccination programs, particularly against the 4/91 IBV strain, in addition to the circulation of many IBV-vaccine-related strains $[18,19]$. Most of the IBVvariant strains have distinctive characteristics due to their global distribution; however, some strains are unique to certain regions, and these properties occur for unknown reasons.

The current work represents the first identifying and genotyping report of IBV that resembles the Israeli isolate in Iraq. The results of the sequencing and phylogenetic tree analysis indicate that our isolate shares $98 \%$ homology with the Israel variant 2 (IS 1494). In 2011, Zana et al. [20] reported a newly isolated strain along with other regionally identified isolates from other Israel strains (IS/720/99, IS/885), and Waleed et al. [21] also registered strains 793/B and Mass from infected broilers in the South of Iraq. Thus, isolates from different parts of Iraq demonstrate large differences in homology. In addition, in the Sulaimaniah isolate (Sul/01/09), the birds displayed nephron pathological lesions, and the virus was detected from kidney samples but not from tracheae. Therefore, the Sulmania (Iraqi strain) that affected broilers differs genetically from our strain that infected layers. Furthermore, our isolate shared $<82 \%$ and $79 \%$ in nucleotide sequence with vaccine strains FJ888351.1 and KX258195.1, respectively, which may explain the occurrence of infection despite vaccination.

Therefore, our work lays the main foundation including RNA-based S1 protein transcript sequencing and the related phylogenetic analysis, to initiate launching strategies for control of IBV in the field.

\section{Conclusion}

Despite the intensive vaccination program in Iraq, IB outbreaks have occurred for many decades. In this study, we isolated a strain of IBV very different from that of local North Iraq (Sulemania Strain) but similar to an Israeli strain (Israel variant 2, IS 1494). Genetic characterization of the Iraqi circulating IBV strains is critical because of inadequate data from this location. More studies revealing such strains will pave the way for a good strategy of controlling the infections and understanding or developing types of vaccines that should be used in the future.

\section{Authors' Contributions}

AOA and HMA visited the infected farm, collected the samples, and performed the rapid IBV antigen detection. FA and YIK visited the infected farm, collected the samples, run the rapid IBV antigen detection, confirmed the results using FTA card that was sent to Germany, deposited the genetic information into the NCBI database, analyzed the differences between the strains of the virus, and drafted the manuscript. All authors revised the manuscript. All authors have read and approved the final manuscript.

\section{Acknowledgments}

The authors thank AniCon Laboratory in Germany for their assistance in the diagnosis of the virus. The work was performed in the College of Veterinary Medicine, University of Al-Qadisiyah, 
Diwaniyah City, Iraq, and the AniCon Labor GmbH (Muehlenstraße 13a 49685 Hoeltinghausen, Germany). The authors did not receive any funds for this study.

\section{Competing Interests} interests.

The authors declare that they have no competing

\section{Publisher's Note}

Veterinary World remains neutral with regard to jurisdictional claims in published institutional affiliation.

\section{References}

1. Bande, F., Arshad, S.S., Omar, A.R., Bejo, M.H., Abubakar, M.S. and Abba, Y. (2016) Pathogenesis and diagnostic approaches of avian infectious bronchitis. Adv. Virol., 2016(Article ID:4621659): 1-11.

2. King, A.M.Q., Lefkowitz, E.J., Mushegian, A.R., Adams, M.J., Dutilh, B.E., Gorbalenya, A.E., Harrach, B., Harrison, R.L., Junglen, S., Knowles, N.J., Kropinski, A.M., Krupovic, M., Kuhn, J.H., Nibert, M.L., Rubino, L., Sabanadzovic, S., Sanfacon, H., Siddell, S.G., Simmonds, P., Varsani, A., Zerbini, F.M. and Davison, A.J. (2018) Changes to taxonomy and the international code of virus classification and nomenclature ratified by the international committee on taxonomy of viruses. Arch. Virol., 163(9): 2601-2631.

3. Valastro, V., Holmes, E.C., Britton, P., Fusaro, A., Jackwood, M.W., Cattoli, G. and Monne, I. (2016) S1 gene-based phylogeny of infectious bronchitis virus: An attempt to harmonize virus classification. Infect. Genet. Evol., 39(2016): 349-364.

4. Hassan, M.S.H., Ojkic, D., Coffin, C.S., Cork, S.C., van der Meer, F. and Abdul-Careem, M.F. (2019) Delmarva (DMV/1639) infectious bronchitis virus (IBV) variants isolated in eastern Canada show evidence of recombination. Viruses, 11(11): 1054.

5. Martin, E., Brash, M., Stalker, M. and Ojkic, D. (2017) Using phylogenetic analysis to examine the changing strains of infectious bronchitis virus infections in Ontario over time. In: Proceedings of the $16^{\text {th }}$ Annual Meeting of the Canadian Animal Health Laboratorians Network, Guelph, ON, Canada. p4-7.

6. Moreno, A., Franzo, G., Massi, P., Tosi, G., Blanco, A., Antilles, N., Biarnes, M., Majo, N., Nofrarias, M., Dolz, R., Lelli, D., Sozzi, E., Lavazza, A. and Cecchinato, M. (2017) A novel variant of the infectious bronchitis virus resulting from recombination events in Italy and Spain. Avian Pathol., 46(1): 28-35.

7. Wickramasinghe, I.N., van Beurden, S.J., Weerts, E.A. and Verheije, M.H. (2014) The avian coronavirus spike protein. Virus Res., 19(194): 37-48.

8. Fellahi, S., El Harrak, M., Kuhn, J.H., Sebbar, G., Bouaiti, E., Khataby, K., Fihri, O.F., El Houadf, M. and
Ennaji, M.M. (2016) Comparison of SYBR green I realtime RT-PCR with conventional agarose gel-based RT-PCR for the diagnosis of infectious bronchitis virus infection in chickens in Morocco. BMC Res. Notes, 2016(9): 231-239.

9. Lounas, A., Oumouna-Benachour, K., Medkour, H. and Oumouna, M. (2018) The first evidence of a new genotype of nephropathogenic infectious bronchitis virus circulating in vaccinated and unvaccinated broiler flocks in Algeria. Vet. World, 11(11): 1630-1636.

10. Sadri, N., Ghalyanchilangeroudi, A., Fallah Mehrabadi, M.H., Hosseini, H., Shayeganmehr, A., Sediqian, M.S., Sediqian, M.S., Jabbarifakhr, M. and Mousavi, F.S. (2019) Genotyping of avian infectious bronchitis virus in Afghanistan (2016-2017): The first report. Iran. J. Vet. Res., 20(1): 60-63.

11. Zhou, H., Zhang, M., Tian, X., Shao, H., Qian, K., Ye, J. and Qin, A. (2017) Identification of a novel recombinant virulent avian infectious bronchitis virus. Vet. Microbiol., 199(2017): 120-127.

12. Manswr, B., Ball, C., Forrester, A., Chantrey, J. and Ganapathy, K. (2018) Evaluation of full S1 gene sequencing of classical and variant infectious bronchitis viruses extracted from allantoic fluid and FTA cards. Avian Pathol., 47(4): 418-426.

13. Ganapathy, K., Ball, C. and Forrester, A. (2015) Genotypes of infectious bronchitis viruses circulating in the Middle East between 2009 and 2014. Virus Res., 2(210): 198-204.

14. Seger, W., Langeroudi, A.G., Karimi, V., Madadgar, O., Marandi, M.V. and Hashemzadeh, M. (2016) Prevalence of avian infectious bronchitis virus in broiler chicken farms in South of Iraq, 2014-2015. Vet. Res. Forum., 7(4): 317-321.

15. Lin, S.Y. and Chen, H.W. (2017) Infectious bronchitis virus variants: Molecular analysis and pathogenicity investigation. Int. J. Mol. Sci., 18(10): 2030.

16. Bande, F., Arshad, S.S., Bejo, M.H., Moeini, H. and Omar, A.R. (2015) Progress and challenges toward the development of vaccines against avian infectious bronchitis. J. Immunol. Res., 2015(Article ID: 424860): 1-12.

17. Guzmán, M., Sáenz, L. and Hidalgo, H. (2019) Molecular and antigenic characterization of GI-13 and GI-16 avian infectious bronchitis virus isolated in chile from 2009 to 2017 regarding 4/91 vaccine introduction. Animals (Basel), 9(9): 656.

18. Wibowo, M.H., Ginting, T.E. and Asmara, W. (2019) Molecular characterization of pathogenic 4/91-like and QX-like infectious bronchitis virus infecting commercial poultry farms in Indonesia. Vet. World., 12(2): 277-287.

19. Legnardi, M., Franzo, G., Koutoulis, K.C., Wiśniewski, M., Catelli, E., Tucciarone, C.M. and Cecchinato, M. (2019) Vaccine or field strains: The jigsaw pattern of infectious bronchitis virus molecular epidemiology in Poland. Poult. Sci., 98(12): 6388-6392.

20. Zana, H.M., Rizgar, R.S. and Aumaid, U.U. (2011) Isolation and molecular characterization of Sul/01/09 avian infectious bronchitis virus, indicates the emergence of a new genotype in the Middle East. Vet. Microbiol., 150(1-2): 21-27.

21. Waleed, S., Arash, G., Vahid, K., Omid, M., Mehdi, V. and Masoud, H. (2016) Prevalence of avian infectious bronchitis virus in broiler chicken farms in south of Iraq, 20142015. Vet. Res. Forum., 7(4): 317-321. 